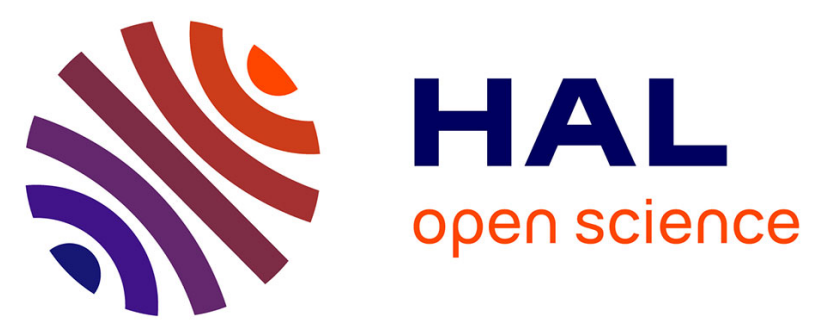

\title{
The effect of boiling in a thermosyphon on surface tension and contact angle of silica and graphene oxide nanofluids
}

Agnieszka Kujawska, Robert Mulka, Samah Hamze, Gawel Żyla, Bartosz

Zajaczkowski, Matthias H Buschmann, Patrice Estellé

\section{To cite this version:}

Agnieszka Kujawska, Robert Mulka, Samah Hamze, Gawel Żyla, Bartosz Zajaczkowski, et al.. The effect of boiling in a thermosyphon on surface tension and contact angle of silica and graphene oxide nanofluids. Colloids and Surfaces A: Physicochemical and Engineering Aspects, 2021, 627, pp.127082. 10.1016/j.colsurfa.2021.127082 . hal-03271647

\section{HAL Id: hal-03271647 \\ https://hal.science/hal-03271647}

Submitted on 26 Jun 2021

HAL is a multi-disciplinary open access archive for the deposit and dissemination of scientific research documents, whether they are published or not. The documents may come from teaching and research institutions in France or abroad, or from public or private research centers.
L'archive ouverte pluridisciplinaire HAL, est destinée au dépôt et à la diffusion de documents scientifiques de niveau recherche, publiés ou non, émanant des établissements d'enseignement et de recherche français ou étrangers, des laboratoires publics ou privés. 


\title{
The effect of boiling in a thermosyphon on surface tension and contact angle of silica and graphene oxide nanofluids
}

\author{
Agnieszka Kujawska ${ }^{a}$, Robert Mulka ${ }^{a}$, Samah Hamze ${ }^{b}$, Gaweł Żyła $^{c}$, Bartosz Zajaczkowski ${ }^{a}$, \\ Matthias H. Buschmann ${ }^{d}$, Patrice Estellé*b \\ ${ }^{a}$ Wroclaw University of Science and Technology, Department of Thermal Sciences, Wybrzeże \\ Wyspiańskiego 27, 50-370 Wrocław, Poland \\ ${ }^{\mathrm{b}}$ Univ Rennes, LGCGM, 35000 Rennes, France \\ ${ }^{c}$ Department of Experimental Physics, Rzeszow University of Technology, Rzeszow, Poland \\ ${ }^{d}$ Institut für Luft- und Kältetechnik gGmbH, Bertolt-Brecht-Allee 20, 01309 Dresden, Germany \\ * Corresponding author: patrice.estelle@univ-rennes1.fr
}

\begin{abstract}
Thermosyphons are heat transfer devices characterized by high efficiency due to simultaneous phase changes occurring in the evaporation-condensation cycle of working fluid. One of the most promising solutions to enhance their heat transfer capacity of the device is the use of nanofluids - suspensions of particles with at least one dimension below $100 \mathrm{~nm}$. It was determined that nanofluid does not influence the work of thermosyphons condenser section and the focus should be put on the boiling process in the evaporator section. During boiling, nanoparticles tend to deposit on the heater's surface, what alters characteristics of this surface and near surface hydrodynamics. This changes the appearance of nanofluid, but the precise effect on how the deposition of particles affects the properties of nanofluid is unknown. Changes in surface tension and wettability affect boiling regimes (e.g. reduced surface tension reduces the size of departing bubbles and inhibits geysering), and efficiency of heat transfer through the device. Understanding of those parameters is crucial for the development of appropriate models describing heat transfer in thermosyphon working with nanofluids. The main goal of this study is to determine surface tension and contact angle of nanofluids based on silica nanoparticles and nano-sized graphene oxide flakes before and after the experimental boiling cycle in the thermosyphon. Results show that, in comparison with water, silica nanofluid ( 2 vol.\%) is characterized by lower surface tension and contact angles on both analysed surfaces. After-use silica nanofluid exhibited noticeably higher averaged surface tension and smaller contact angles in comparison to the fresh working medium. The change was most likely due to the decreased concentration caused by the deposition of nanoparticles during the thermosyphon operation. Still, the differences between before-use and after-use samples were smaller than the measurement uncertainties. Before-use graphene oxide nanofluid already showed surface tension and contact angle similar to water due to low concentration of graphene flakes $(0.1 \mathrm{~g} / \mathrm{L})$. Consequently, the properties of after-use graphene oxide fluid were also not much different from water. Additional measurements of surface tension for graphene oxide nanofluid with and without addition of sodium dodecyl sulfate surfactant allowed to differentiate the effects caused by graphene flakes and surfactant. The surfactant reduced the surface tension of the nanofluid, but the change was smaller than in case of surfactant addition to pure water.
\end{abstract}

\section{Keywords}

Surface tension, contact angle, silica nanofluid, graphene oxide nanofluid, boiling, thermosyphon 


\section{Nomenclature}

$a, b, c, D$ coefficients

CA contact angle, ${ }^{\circ}$

d diameter, $\mathrm{m}$

$d_{b f} \quad$ fluid molecule parameter

DLS Dynamic light scattering

GO graphene oxide nanofluid

SDS sodium dodecyl sulfate (surfactant)

SEM Scanning electron microscope

$t$ temperature, ${ }^{\circ} \mathrm{C}$

$V \quad$ volume, $\mathrm{dm}^{3}$

\section{Greek symbols}

$\theta \quad$ contact angle, ${ }^{\circ}$

$\rho$ density, $\mathrm{g} / \mathrm{cm}^{3}$

$\phi \quad$ particle volume fraction, -

$\sigma \quad$ surface tension, $\mathrm{mN} / \mathrm{m}$

\section{Subscripts}

bf basefluid

$d r \quad$ droplet

fl fluid

nf nanofluid

np nanoparticles 


\section{Introduction}

Thermosyphons are heat exchangers characterised by high heat transfer efficiency, lack of mechanical parts, and adaptability to given working requirements. Due to simultaneous phase changes in the evaporation-condensation cycle of the working fluid, the apparent thermal conductivity of thermosyphons is several orders of magnitude higher than those of metals like copper or silver [1]. The first reported thermosyphon (in the middle of the $19^{\text {th }}$ century) was the Perkins tube, which transported heat from a furnace to a steam boiler evaporator [2]. Since that time, thermosyphons have been used in various applications, such as geothermal systems, preservation of permafrost, snow melting and de-icing, nuclear reactors, heat exchangers, cooling of electronics, or solar energy storage systems [1-4].

A two-phase closed thermosyphon is a sealed, pressurised container filled with purposely selected working fluid. The device is divided into three sections (from the bottom): evaporator where heat absorption takes place, insulated adiabatic section, and condenser where heat is released. When external sources of heat are supplied in sufficient amounts to the evaporator, the working fluid accumulated in the lower part of the device starts to evaporate. Bubbles grow in the fluid and vapour raises through the adiabatic section to the upper part - condenser. Through contact with the colder condenser walls, the vapour condenses and the heat is released to the external cooling medium. The condensate forms a falling film or rivulets that return to the boiling pool in the evaporator due to gravity forces. For this reason, the device must be positioned either vertically or slightly inclined, with the evaporator remaining below the condenser. This requirement distinguishes thermosyphons from heat pipes. The latter usually rely upon capillary structures (condensate is carried back to the evaporator by means of capillary, osmotic or electrostatic forces) or oscillations (the movement of condensate liquid slugs interspersed with vapour bubbles is a result of pressure differences).

One promising solution to enhancing heat transfer efficiency of thermosyphons is the usage of nanofluids instead of common heat transfer fluids, such as water or glycols. Nanofluids are defined as suspensions of nano-objects with at least one dimension smaller than $100 \mathrm{~nm}$ [5], while nanoparticles indicate nano-objects with all spatial dimensions smaller than $100 \mathrm{~nm}$ [6]. The term 'nanoparticle' is commonly used for both nano-objects and nanoparticles $[5,7,8]$, and is used in a similar context in this paper.

Literature offers several comprehensive reviews on thermosyphons and heat pipes using nanofluids as working fluids [9-13]. Deeper look into thermosyphons working with nanofluids, including graphene-based and silica particles has been presented in our earlier papers [14,15], and thus are not repeated here. Many studies show that nanofluids may improve heat transfer capabilities of the thermosyphon $[7,9,14,16-19]$. Literature agrees that the effect of nanofluids on the condenser section is negligible [9,20-22], and thus focus should be put on the evaporator section and the boiling process. Results suggest that the main improvement in heat transfer capabilities of the thermosyphon comes from the interplay between nanoparticles, evaporator surface, and bubble release during boiling.

Boiling heat transfer is influenced by many parameters that can be divided into three groups: thermophysical properties of the working fluid, characteristics of the heater surface, and near surface hydrodynamics. During the boiling of nanofluids, nanoparticles tend to deposit on the heater surface (evaporator in thermosyphon), which alters the characteristics of this surface and nearsurface hydrodynamics [23-29], and it was closely analysed in detail in our previous works $[7,14,15,20]$. This paper focusses on the third group - thermophysical properties of working fluids 
(surface tension) and their interaction with the heater surface (wettability) with the aim of investigating whether these properties change over time during the operation.

Surface tension appears in many heat transfer correlations, such as Bond number, critical heat flux, or Kutateladze number. The most common surface tension measurement methods are [30] [31,32]: pendant drop, Wilhelmy plate, maximum bubble pressure, Du Noüy Ring, capillary rise and spinning drop techniques.

The presence of nanoparticles change the surface tension of the base fluid, but the current state of knowledge still cannot precisely explain the mechanisms behind the change. A recent review [30] showed that surface tension of nanofluids is affected mostly by the: type of nanoparticles and base fluid, (lack of) surfactant addition, temperature, particle size and shape, and concentration. $\mathrm{Al}_{2} \mathrm{O}_{3}$ is the most studied nanofluid with respect to the surface tension measurements. $\mathrm{SiO}_{2}$-based nanofluids were described in only a few papers [33-36], which differ by the type of used base fluid (water, methanol, glycol, and PDMS), way of preparation, size of particles, and temperature range. In general, silica-based nanofluids are characterised by lower surface tensions than e.g. $\mathrm{TiO}_{2}$ and $\mathrm{Al}_{2} \mathrm{O}_{3}$ nanofluids with the same concentration of particles. In most studies, surface tension raises with increasing concentration of $\mathrm{SiO}_{2}$ nanoparticle and decreasing temperature. Graphene materials exhibit confusing increase $[37,38]$ or decrease $[39,40]$ in surface tension with increasing concentrations. In all these studies, surface tension is reduced with an increase in temperature. Reliable and comparable results with a wide range of parameters are still required for the development of universal correlations and models. Although surface tension is an important parameter in heat transfer correlations, there are wide gaps in the knowledge on how the boiling process affects surface tension of graphene oxide and silica nanofluids.

The contact angle (CA), defined as the angle between the solid substrate and nanofluid interface, is a measure of wettability of a solid by a liquid. So far, the understanding of the contact angle of nanofluids is very narrow, and the most comprehensive review of studies was presented by Hernaiz et al. [41]. CA depends on the type and properties of solid and its surface, characteristics of a liquid and surrounding fluid, temperatures of all media, and the size of analysed droplet [42-46]. Adding nanoparticles to the liquid makes these dependencies more complex, as a nanofluid itself should be considered as a two-phase liquid-solid substance [41]. Moreover, existing theoretical models that describe the contact angle of single-phase droplets require experimentally determined details (e.g. droplet baseline radius, apex height and curvature), so this approach is not practical for engineering applications.

Wettability plays an important role in the boiling process [47-50], thus the understanding of how nanofluids affect the contact angle on a given surface is of high importance to enabling the formulation of correlations and models applicable for a wide range of materials and temperatures. Kim et al. [51] studied changes in contact angle of water on heater surfaces previously used for boiling of $\mathrm{Al}_{2} \mathrm{O}_{3}, \mathrm{ZrO}_{2}$, and $\mathrm{SiO}_{2}$ nanofluids. They found that the earlier-deposited nanoparticles covering the heater's surface decrease the contact angle during subsequent boiling of water on the same surface. Apparently, the layer of nanoparticles reduced density of the active nucleation sites. Sarafraz et al. [52] performed similar study for carbon nanotubes dispersed in water. Pham et al. [53] studied both carbon nanotubes and alumina nanofluids, while Truong et al. [54] looked into diamond, alumina, and zinc oxide nanofluids. All above-mentioned papers report that the surface changes caused by nanoparticles deposition decrease the contact angle of water droplets. More recently, Gimeno-Furio et al. [55] investigated the wettability properties of carbon nanohorn water based nanofluids, considering the impact of nanohorn oxidization and concentration. They also originally reported their coating ability on metal surfaces from pool boiling. To the best of the 
authors' knowledge, there is no comparative study on how boiling affects the wettability and surface tension properties of silica and graphene oxide nanofluids. There is an endless number of nanofluids combinations, including used nanoparticles, base fluid, concentration, size, surfactant, etc. In our previous studies $[7,14,15]$ we analysed different types of nanofluids with respect to application in thermosyphon. The nanofluids were chosen to address various research concerns, such as whether high thermal conductivity (gold, graphene oxide) and high specific surface area (nanohorns, graphene oxide) of nanoparticles are crucial for boiling applications, the impact of film-forming properties (silica), or the impact of surfactant addition (water solution of sodium dodecyl sulfate). Among all tested combinations, the highest improvement in heat transfer capabilities of thermosyphon for low heat loads was gained by usage of silica nanofluid, followed by graphene oxide nanofluid. Moreover, silica nanofluid suppressed geyser boiling, what may increase lifetime and stability of the device. Since these nanofluids keep a promise for heat transfer and reliability improvements, what motivates our choice of nanofluids for further experimental research shown in this paper.

During boiling of the nanofluid, when nanoparticles are transferred onto the surface, the composition and appearance of the working medium must also change. As a consequence, the properties of nanofluid most certainly depend on time and temperature. This fact is generally neglected in the literature. The properties of nanofluids are usually evaluated only prior to the main series experiments and usually at the ambient temperature. The main goal of this paper is thus to determine surface tension and contact angle of nanofluids based on silica nanoparticles and graphene oxide flakes before and after completing experimental boiling series in the thermosyphon. This research will help to analyse the time-dependent behaviour of thermosyphons working with nanofluids, which could lead to more appropriate models and correlations in the future.

\section{Methodology}

\section{a. Investigated working fluids}

Water and two types of water-based nanofluids (with silica nanoparticles and graphene oxide flakes) were investigated with respect to the surface tension of the fluid and contact angle on two different surfaces. For both nanofluids, two samples were tested: a fresh 'before-use' nanofluid (prepared to be used as a working medium), and the 'after-boiling' fluid taken out of the thermosyphon after completing all the measurement series in the device.

The inlet temperature of cooling water removing heat from the condenser section was set at $25^{\circ} \mathrm{C}$. One experimental series for a given working fluid included measurements at steady-state conditions for the temperature of heating water in the range between $35^{\circ} \mathrm{C}$ and $65^{\circ} \mathrm{C}$ in $5^{\circ} \mathrm{C}$ steps. Once the first series had been completed, the measurements were repeated to check the influence of nanoparticle deposition into layers on the inner wall of the evaporator. After finishing all experimental points, the working fluid was removed from the device and it has been once again evaluated. More details on the experimental setup and the procedure, as well as detailed results can be found in [15].

Water-based silica nanofluid (Fig. 1) prepared by Fraunhofer- Institut für Keramische Technologien und Systeme IKTS was previously used as a working fluid in a thermosyphon [15]. The raw material (SIPERNAT 22S) was dispersed unfractionated with higher concentration and then diluted to a concentration of $2 \%$ vol. The addition of $\mathrm{KOH}$ ensured a $\mathrm{pH}$ value of 10.5 , which is required when working with copper tubes. When preparing suspensions, it is customary to adjust the $\mathrm{pH}$ value and to check this with the $\mathrm{pH}$-meter. However, how many milliliters of $\mathrm{KOH}$ lye are dosed is not recorded as standard. In the case of the employed silica nanofluid, the adjustment of the $\mathrm{pH}$ value is carried out according to DIN 19268:2007-05 (DIN 19268 - 2007-05 - Beuth.de). A pH-Meter Seven Multi 
(Mettler-Toledo $\mathrm{GmbH}$, Gießen, Germany) was utilised to this end. However, the $\mathrm{KOH}$ content is too low for possibly having an effect on nanofluid density. The mean size silica nanoparticles was measured by the manufacturer using the DLS method (Zetasizer Nano ZS, Malvern Instruments $\mathrm{GmbH}$, Germany). DLS provides the two most common options to calculate the size of particles: xDLS (also called Z-average) or quantile calculation from size distribution. The most popular $50 \%$ method (x50) of the latter determines the size for which $50 \%$ of the total distribution are smaller than this size. In the case of fresh silica nanofluid, the values were $118 \mathrm{~nm}$ (xDLS) and $80 \mathrm{~nm}$ (x50). Thermal conductivity of an analogous sample measured using a ring gap apparatus [56] was characterised by $2 \%$ (at $20-30^{\circ} \mathrm{C}$ ) to $1 \%\left(\right.$ at $60^{\circ} \mathrm{C}$ ) higher values than water [7]. More details on the fluid including SEM analysis of samples before and after boiling are presented in [15].

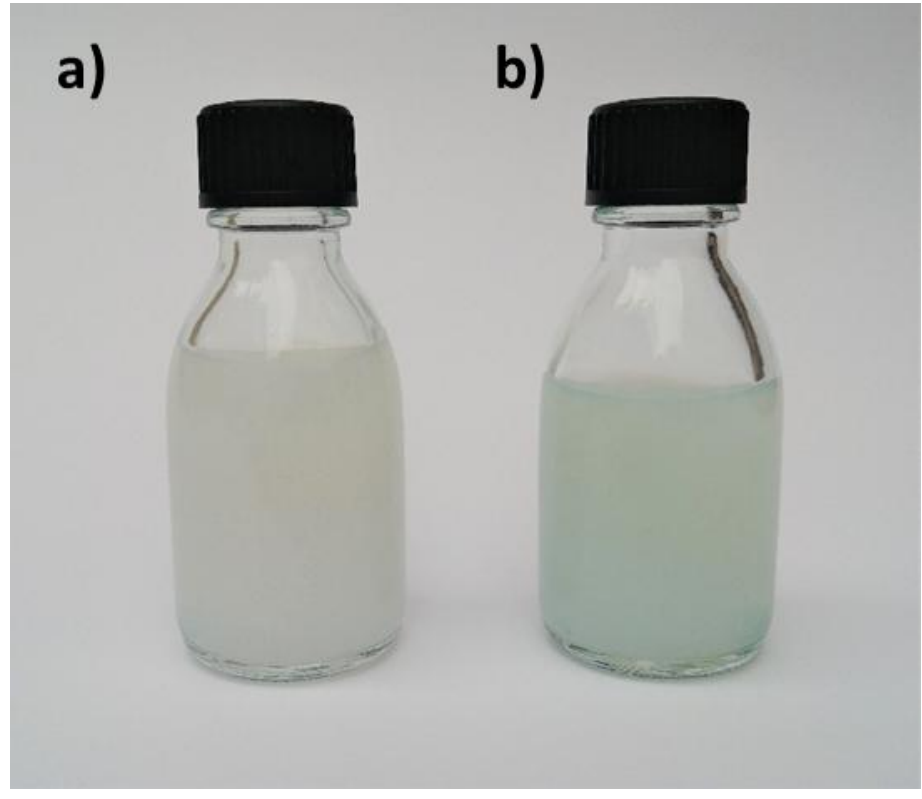

Fig. 1. Silica nanofluid: a) freshly prepared, b) fluid after completing all experimental series in the thermosyphon.

Figure 2 presents samples of graphene oxide (GO) nanofluid before and after completing experimental series in thermosyphon. GO flakes have been synthesized at Institute of Electronic Materials Technology (Warsaw, Poland) by means of the modified Hummers method. The concentrated solution of graphene oxide (without any chemical stabilizer) was diluted to ensure a concentration of $0.1 \mathrm{~g} / \mathrm{L}$. The preparation procedure and the SEM analysis of particles in samples obtained before and after boiling in the thermosyphon has been detailed in Wlazlak et al. [14]. The study showed that structures remaining in the sample after boiling lost the flake-shape and became highly irregular in both shapes and sizes. Additionally, both graphene oxide nanofluids (with and without SDS surfactant) have been analysed fresh (before boiling) with respect to the surface tension. The goal was to evaluate the influence of graphene oxide flakes from the surfactant effect on the surface tension of nanofluid. The current study is complementary to our previous study [14] which focussed on the thermal analysis of thermosyphon operating with a nanofluid based on graphene oxide. 


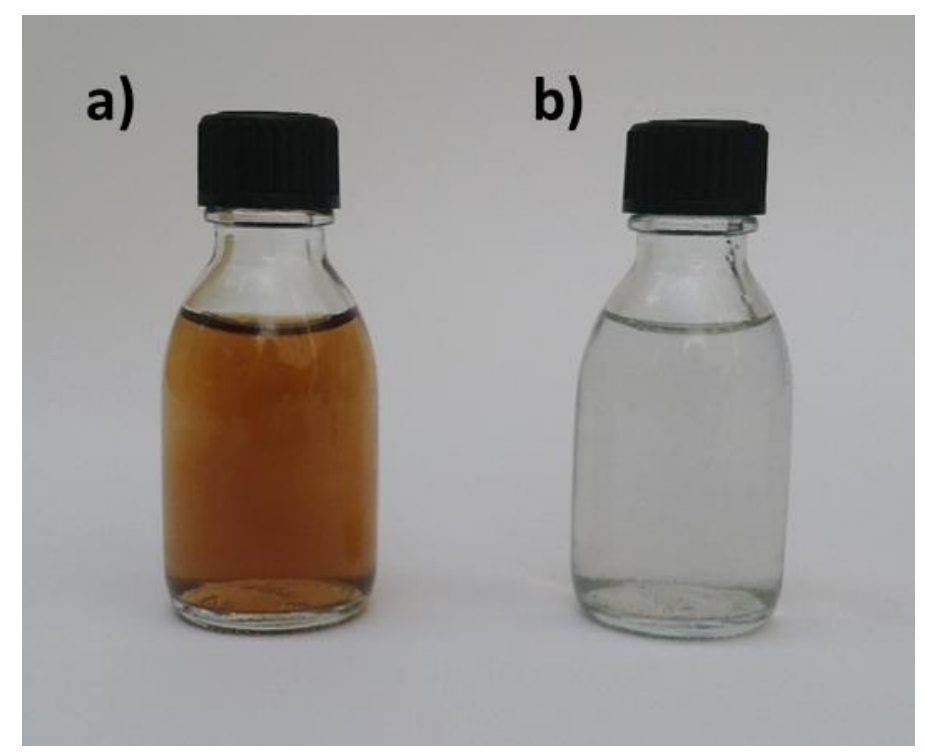

Fig. 2. Graphene oxide nanofluid before boiling (a) and after boiling in the thermosyphon (b).

The appearance of samples before boiling have not changed for at least 6 months and no signs of nanofluids deterioration was observed. Figures 1 and 2 show notable visual differences between the before-use and after-use samples for both investigated nanofluids. This observation, supported by the observation nanoparticle deposition on the heater's surface [14], motivated the questions about the degree of changes in fluid properties and the present study.

\section{b. Experimental set-ups}

Surface tension measurements have been carried out using two devices: DSA-30 Drop Shape Analyzer (KRÜSS GmbH, Germany) and Tension meter PI-MT1A.KOM (Polon-Izot, Poland). The Analyzer was used to measure samples before and after boiling, while the tension meter was used for additional measurements of graphene oxide nanofluid with and without addition of surfactant (SDS). The differences in surface tension of fresh graphene oxide nanofluid determined by both devices were not statistically significant, in agreement with earlier reports $[57,58]$.

The DSA-30 Drop Shape Analyzer uses the pendant drop method. The device is equipped with an environmental chamber which allowed for measurements in the temperature range from $15^{\circ} \mathrm{C}$ to $75^{\circ} \mathrm{C}$ with an $0.1^{\circ} \mathrm{C}$ accuracy. Measurements are conducted in the steady-state condition using a needle with an outer diameter of $1.835 \mathrm{~mm}$ fixed vertically to a syringe. The software uses the Young-Laplace equation for evaluation of both internal and external forces acting on the droplet at the end of the needle for the entire range of temperatures. The initial calibration of the system is conducted by measuring distilled water and validating the results with the confirmed values from literature. To ensure stability of working conditions (humidity, air temperature etc.) measurements start immediately after formation of the drop. The uncertainty is lower than $1.1 \%$ [59].

Tension meter PI-MT1A.KOM relies upon Noüy's ring method. The analytical balance of the ring with a diameter of $9.6914 \mathrm{~mm}$ is determined with a mass uncertainty of $0.0001 \mathrm{~g}$. Surface tension is calculated using the maximum force necessary to pull up the ring, just before detachment. Temperature of the sample $(20 \mathrm{~mL})$ placed in a vessel is controlled by a Peltier system at $0.1^{\circ} \mathrm{C}$ accuracy. The final values are the average of ten measurements. The uncertainty is $2 \%$ for water and $1 \%$ for pure EG [57]. 
The measurements of surface tension require information on fluid's density. Literature provided reasonably accurate values for water density [60]. Densities of both silica samples were estimated at each measured temperature using the mixture rule [42]:

$$
\rho_{n f}=\varnothing \rho_{n p}+(1-\varnothing) \rho_{b f},
$$

where $\varnothing$ is the particle volume fraction (2\%), $\rho_{n p}$ is the true density of nanoparticles $\left(2 \mathrm{~g} / \mathrm{cm}^{3}\right)$, and $\rho_{b f}$ is the density of base fluid (water). Due to low amount, it is assumed that the addition of $\mathrm{KOH}$ has negligible effect on density.

Densities of graphene oxide nanofluids have been determined experimentally by Hernaiz et al. [41] for a temperature range of $10-60^{\circ} \mathrm{C}$ using an Anton Paar DSA 5000 with an uncertainty of $0.5 \mathrm{\mu g} / \mathrm{cm}^{3}$. For higher temperatures $\left(65-75^{\circ} \mathrm{C}\right)$, the approximate values have been calculated using equation (1). The results are shown in Table 1.

Table 1. Density of graphene oxide (GO) water-based nanofluid with concentration of $0.1 \mathrm{~g} / \mathrm{L}$, and $\mathrm{GO}$ nanofluid with addition of $0.01 \mathrm{~g} / \mathrm{L}$ of surfactant SDS. $t$ - temperature, $\rho$ - density [41].

\begin{tabular}{|l|l|l|l|l|l|l|l|l|l|l|l|l|l|}
\hline $\mathbf{t}\left[{ }^{\circ} \mathrm{C}\right]$ & $\mathbf{1 5}$ & $\mathbf{2 0}$ & $\mathbf{2 5}$ & $\mathbf{3 0}$ & $\mathbf{3 5}$ & $\mathbf{4 0}$ & $\mathbf{4 5}$ & $\mathbf{5 0}$ & $\mathbf{5 5}$ & $\mathbf{6 0}$ & $\mathbf{6 5}$ & $\mathbf{7 0}$ & $\mathbf{7 5}$ \\
\hline$\rho_{\mathrm{GO}}\left[\mathrm{g} / \mathrm{cm}^{3}\right]$ & 1.000 & 0.998 & 0.997 & 0.996 & 0.994 & 0.992 & 0.990 & 0.988 & 0.986 & 0.983 & 0.981 & 0.979 & 0.977 \\
\hline $\begin{array}{l}\rho_{\mathrm{GO}+\mathrm{SDS}} \\
{\left[\mathrm{g} / \mathrm{cm}^{3}\right]}\end{array}$ & 1.007 & 1.004 & 1.001 & 0.998 & 0.995 & 0.993 & 0.990 & 0.987 & 0.984 & 0.981 & 0.977 & 0.974 & 0.971 \\
\hline
\end{tabular}

The density of the GO sample after boiling has been assumed equal to the density of water due to the full transparency of the fluid (with just a few visible micro-scale agglomerates) and a very small difference in density between before-use GO nanofluid and water.

Contact angles have been determined at the ambient condition (the temperature is later reported in Table 2 and $35 \% \pm 5$ in relative humidity) using the DSA-30 Drop Shape Analyzer based on sessile drop method. Measurements started with the calibration using 15-gauge needle with outer diameter of 0.5 and $1.835 \mathrm{~mm}$ fixed to a syringe. Droplets were produced with a controlled volume and flow rate and then deposited on the testing surfaces. The first surface was a stainless steel substrate with a disc shape of $20 \mathrm{~mm}$ in diameter and $5 \mathrm{~mm}$ in height. It has a mean roughness index $R_{a}$ of $0.20 \mu \mathrm{m}$ and an averaged surface roughness $R_{z}$ of $1.56 \mu \mathrm{m}$ as characterized in detail by Hernaiz et al. [41]. The second one is a smooth copper tube with roughness of about $0.6 \mu \mathrm{m}$, this tube is similar to the one initially used for thermosyphon experiments. Each droplet has been recorded immediately after its deposition on the surface with a frequency of $1 \mathrm{~Hz}$ for 15 seconds. Measurement uncertainty was $0.52 \%[39]$.

Analysis of boiling process in the thermosyphon is described in details in [8]. Since the samples analysed here are before and after the boiling in thermosyphon, we summarize the methodology. The experiments were conducted in a 1000-mm-long copper thermosyphon with an inner diameter of $20 \mathrm{~mm}$ and a wall thickness of $1 \mathrm{~mm}$. Boiling took place in the evaporator heated by circulating water in a tube-in-tube exchanger with an external diameter of $35 \mathrm{~mm}$. The experimental procedure includes filling the thermosyphon with $85 \mathrm{ml}$ of a given nanofluid, ensuring the stable vacuum conditions inside the thermosyphon, and conducting the measurements. One series consists of increasing the inlet heating water temperature from $35^{\circ} \mathrm{C}$ to $65^{\circ} \mathrm{C}$ in $5 \mathrm{~K}$ steps. The cooling water was kept constant at $25^{\circ} \mathrm{C}$. The series was then repeated to check if the thermosyphon performance changed after nanoparticle deposition on the heater surface. After all series finished, the working fluid was removed from the device and this sample is referred to 'after boiling' in this paper. Each nanofluid was tested in the new copper pipe to avoid any contamination from the previous 
experiments and no cleaning procedure was applied after each test. The nanofluid samples and deposition on the copper evaporator were later analysed using SEM and the results can be found in [8]. It can be noted that a similar SEM analysis of surfaces before and after pool boiling of nanohorn nanofluids was also done in [55].

\section{Results and discussion}

\section{a. Surface tension}

Measurements of surface tension using the pendant drop method started with calibration of the DSA - 30 Drop Shape Analyzer with distilled water (water - measurements). Obtained results were compared to the literature values [60] (water - literature), as presented in Fig. 3. The average difference between measured and literature values was slightly below $0.6 \%$ in the temperature range $15-75^{\circ} \mathrm{C}$.

Figure 3 compares the surface tension of silica samples: fresh silica nanofluid (silica) and a sample taken from the thermosyphon after completing boiling experiments (silica - boiling). During the measurements, the surface tension decreased with time until the droplets fell down for both silica samples. This behaviour limited the time window to capture images and estimate surface tension. Presented results are averaged for all the droplets observed during the first 20 seconds after the first droplet was formed at the edge of the needle. The exception was the sample of silica after boiling at the temperature of $75^{\circ} \mathrm{C}$. In that case, the averaging time was reduced to 10 seconds because droplets became unstable and fell down after this time period.

Both silica samples were characterised by $4 \%$ - $9 \%$ lower surface tensions in comparison with water, with no additional surfactant being used to stabilise the suspension. As explained by Lu et al. [36], surface tension is determined by the imbalance acting on the liquid molecules present on the interface due to van der Waals forces. Liquid molecules interact with less molecules at the interface than in the volume, thus the liquids minimise possible surface area, which is beneficial from an energy point of view. Silica nanoparticles repulse water molecules, i.e. the molecular spacing on the free surface increases and the attraction forces between the water molecules in the liquid volume and on the free surface regions decrease. In consequence, the surface tension of the nanofluid is lower than the base fluid, which was confirmed by Chinnamm et al. [61] for $\mathrm{SiO}_{2}$ nanoparticle concentration up to 6 vol.\%. This reduced surface tension of silica nanofluid had a significant impact on the boiling behaviour of silica, affecting boiling regimes and suppressing geyser boiling behaviour [7].

Fitted trend lines in Figure 3 show that the after-use silica nanofluid had slightly higher averaged surface tension compared with the fresh nanofluid. The apparent increase is due to reduced concentration of nanoparticles in the medium, as some of the solid material was deposited on the inner wall of the thermosyphon. Still, the measured differences are within the uncertainty range. 


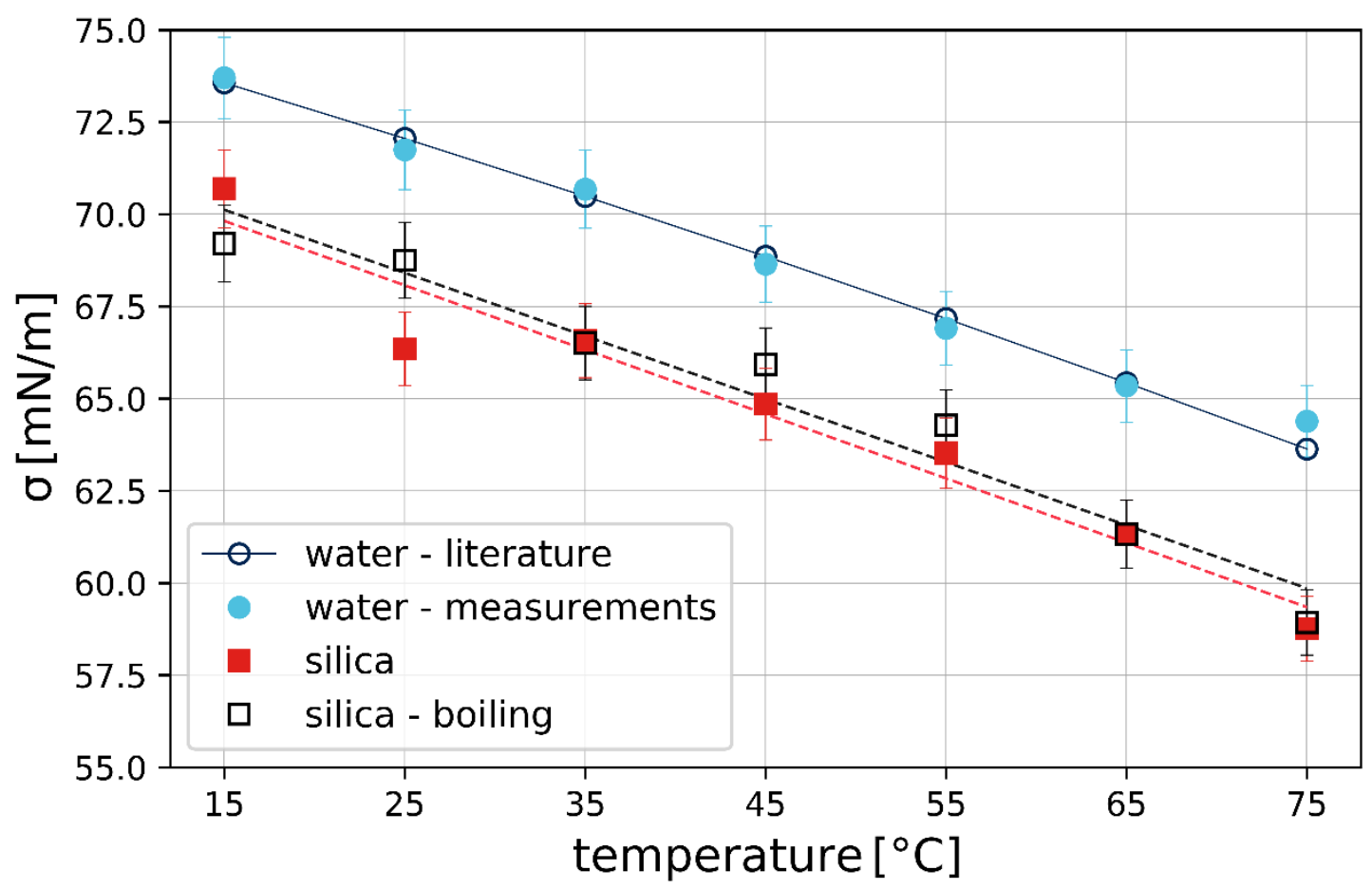

Fig. 3. Surface tension of silica nanofluid in comparison with water: fresh silica nanofluid before (silica) and after (silica - boiling) experimental research in the thermosyphon. Water-measurements are the results obtaining during calibration of the device with distilled water and are compared with literature values (water - literature) [60]. Uncertainty bars represent standard deviation.

The addition of graphene oxide flakes had a negligible effect on the surface tension of the fluid (Figure 4). Due to the small concentration of GO $(0.1 \mathrm{~g} / \mathrm{L}, 0.01$ wt.\%, or 0.005679 vol.\%), the differences between water and both nanofluid samples are within the measurement uncertainty for the entire temperature range $\left(15-75^{\circ} \mathrm{C}\right)$. The results confirm that the surface tension does not influence boiling regimes nor heat transfer capacity of the thermosyphon filled with GO nanofluid [14], in contrast to silica nanofluid that supress geyser boiling at high evaporator temperatures [7]. 


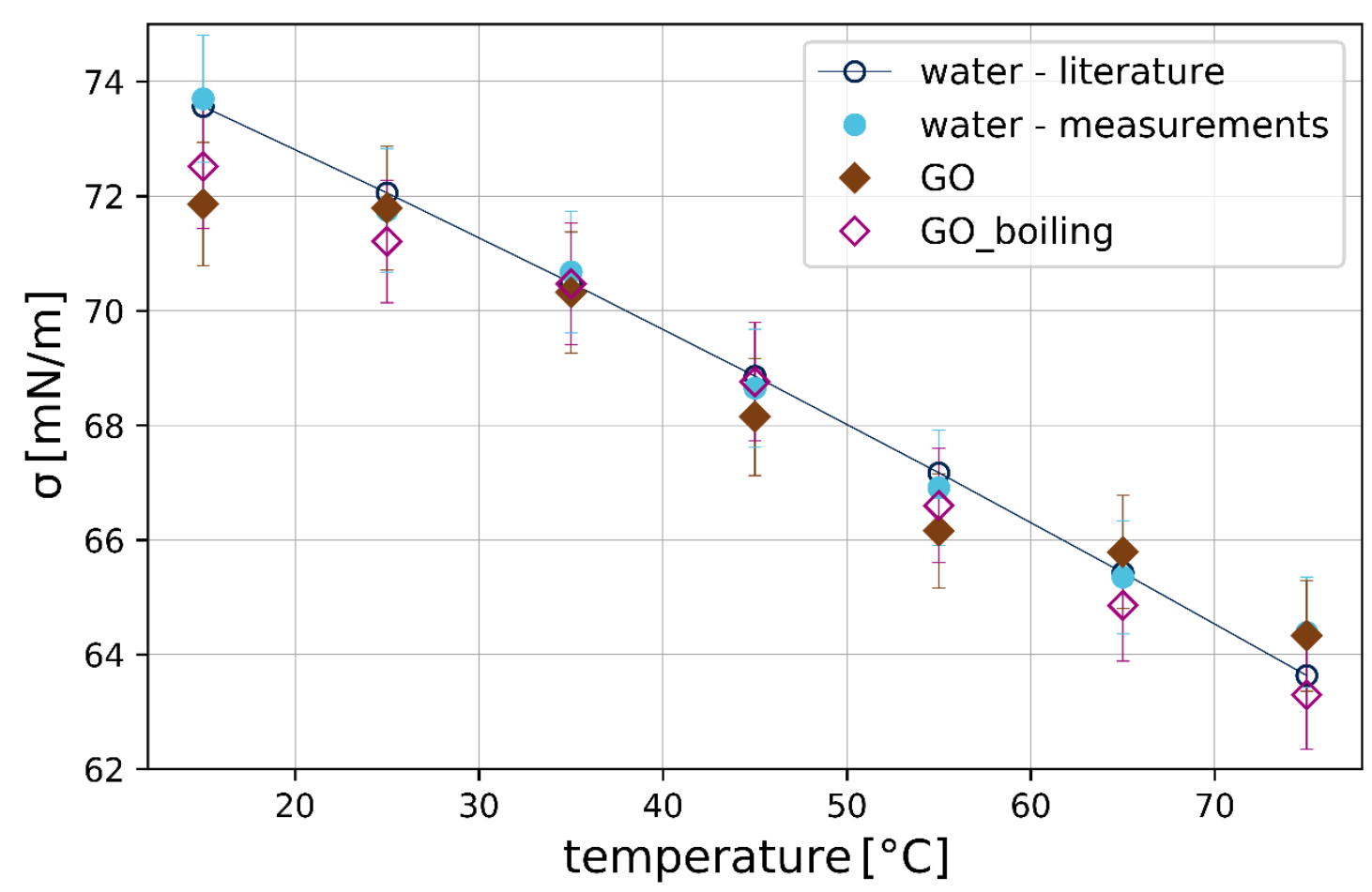

Fig. 4. Surface tension of nanofluid based on graphene oxide flakes in comparison with water: fresh graphene oxide nanofluid before $(G O)$ and after (GO_boiling) experimental research in the thermosyphon.

Uncertainty bars represent standard deviation.

In our previous study [14], we analysed the influence of anionic surfactant SDS (sodium dodecyl sulfate) addition in the amount of $0.01 \mathrm{~g} / \mathrm{L}$ to the same $\mathrm{GO}$ nanofluid. To distinguish the effect caused by graphene flakes from the impact of surfactant, a water solution of the SDS with the same concentration was tested. Here, surface tensions of GO (GO in Fig. 5) and GO+SDS nanofluids $(G O+S D S)$ and SDS solution (SDS solution) were additionally measured as complementary to previous research in thermosyphons [14].

Even a small amount of SDS reduced surface tension of the SDS solution by about $2 \%$ in comparison to water (Fig. 5), which in consequence inhibited geysering by preventing formation of bubbles in sizes similar to the tube diameter. Reduced surface tension led to stable boiling with continuously growing and detaching of small diameter bubbles [14].

GO with the comparable amount of SDS permit geysering because SDS crystals tend to attach to the surface of GO flakes [14], consequently reducing surfactant concentration in the bulk fluid and increasing surface tension in comparison to pure SDS solution (see Figure 5). The formation of large bubbles during boiling is no longer supressed and GO+SDS nanofluid behave similar to water. 


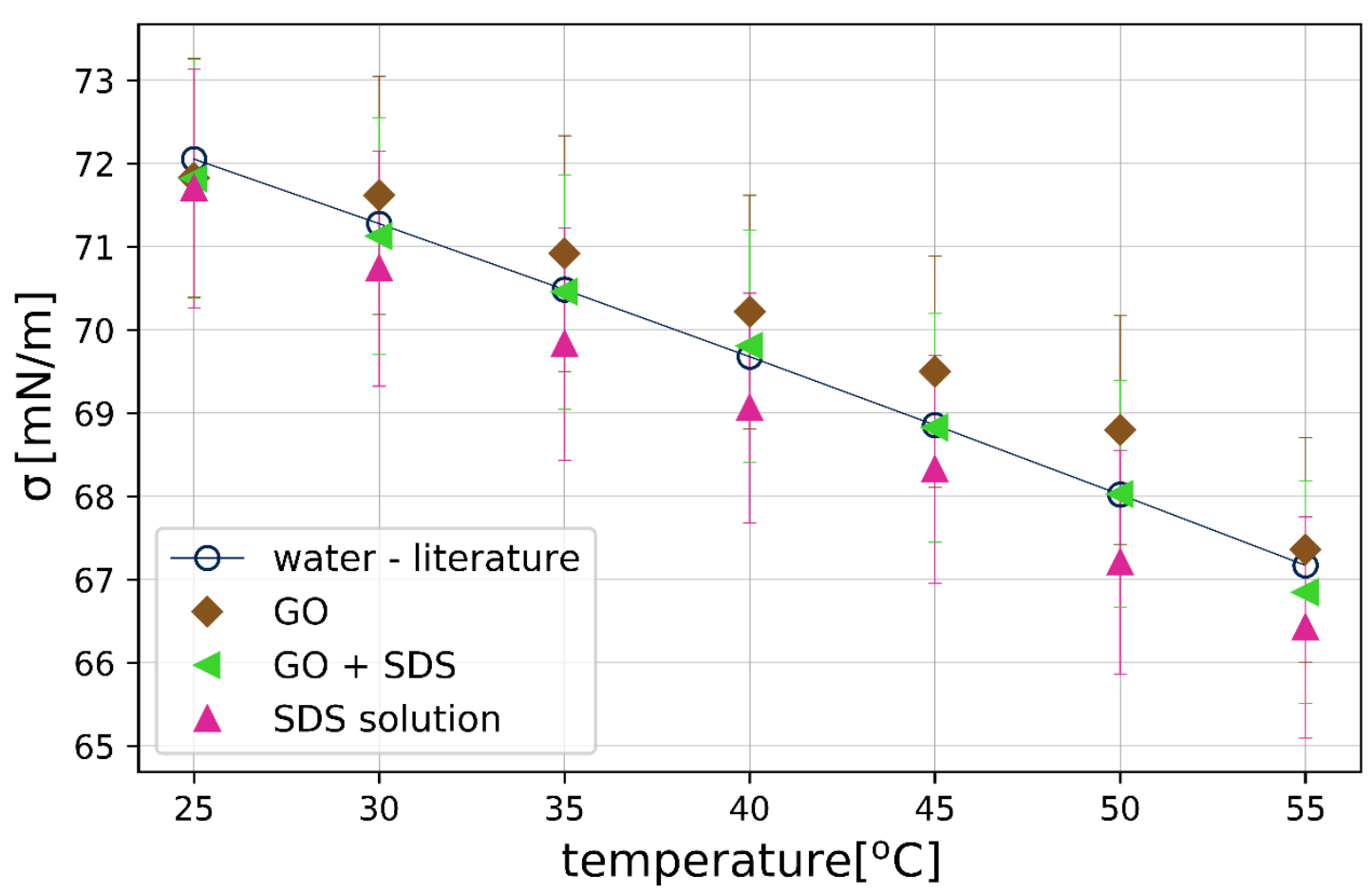

Fig. 5. Surface tension of nanofluids based on graphene oxide flakes $(G O)$, with addition of SDS surfactant $(G O+S D S)$, in comparison with water and SDS water solution (SDS solution). Error bars represent measurement uncertainty.

\section{b. Contact angle}

The results presented in Table 2 (contact angles on a stainless-steel substrate) and Table 8 (a copper tube) are the averaged values of all measured points for each droplet at the ambient temperature. For each droplet, the correctness of each measured data point in a set of observations was assessed using Chauvenet's criterion. It should be noted that the left and right angles are the same, as shown in Figures 6 and 7, evidencing the symmetry of the nanofluid droplets.

\section{- Stainless steel substrate}

The addition of graphene oxide flakes did not change the contact angle of fluid droplets on the stainless-steel substrate within the experimental uncertainty range (Table 2). This was most likely due to the small concentration of $\mathrm{GO}$ flakes $(0.1 \mathrm{~g} / \mathrm{L})$. With the same concentration and substrate, a similar CA value was reported in [55] for water-based carbon nanohorn nanofluids (within the experimental uncertainties in both studies). Therefore, the results after boiling were also similar to water. The standard deviation of GO nanofluid measurements increased in comparison with water because of the movement of particles inside the droplet. The after-use sample exhibited standard deviation lower than the fresh GO nanofluid and higher than water. This was an effect of the reduced number of flakes in the sample after boiling compared to the fresh nanofluid, but still some flakes or agglomerates were present in the fluid.

Silica nanofluid showed the best wettability on the stainless-steel surface. The droplets had about $30-32 \%$ smaller contact angles than water and GO nanofluid. According to Chinnam et al. [35], silica nanoparticles may have sizes orders of magnitude greater, as well as higher density and mass than 
the liquid molecules. This exerts additional downward force on the droplet, which squeezes the droplet towards the solid surface, and in consequence reduces the contact angle. Boiling had negligible effect on the contact angle of silica nanofluid.

Measurements of silica nanofluid produced the highest standard deviation due to it having the highest nanoparticle concentration among all the investigated samples (2 vol.\%). The standard deviation was slightly reduced for the sample after boiling, but both samples had higher standard deviations than water and GO nanofluid.

Table 2. Averaged contact angles between stainless steel substrate [41] and droplets of investigated fluids at the ambient temperature. $C A$ - contact angle, $\sigma$-standard deviation, Vol - volume of the droplet during measurement, Temp - current ambient temperature.

\begin{tabular}{|l|ccc|}
\hline Sample & $\mathbf{C A} \pm \sigma\left[^{\circ}\right]$ & Vol $[\mu \mathrm{L}]$ & Temp $\left[{ }^{\circ} \mathrm{C}\right]$ \\
\hline Water & $72.1 \pm 1.02$ & 5.2 & 20.9 \\
GO nanofluid & $73.2 \pm 3.91$ & 4.3 & 22.2 \\
GO after boiling & $73.6 \pm 2.92$ & 4.4 & 22.4 \\
Silica nanofluid & $50.1 \pm 5.53$ & 5.0 & 21.2 \\
Silica after boiling & $49.8 \pm 4.87$ & 4.9 & 21.2 \\
\hline
\end{tabular}

Illustrative pictures of droplets during measurements on the stainless steel substrate can be seen in Fig. 6.
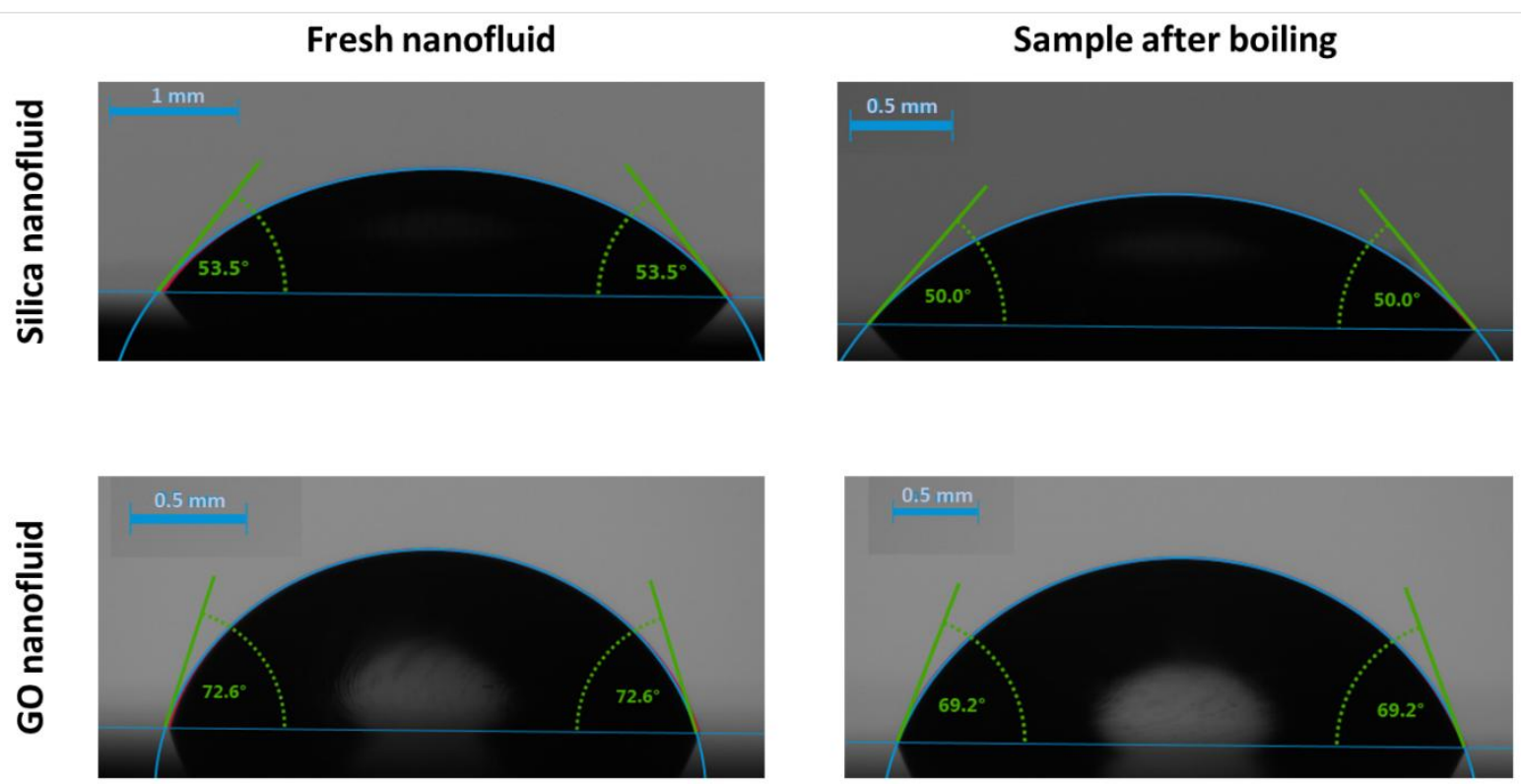

Fig. 6. Examples of measured droplets of silica nanofluid samples on stainless steel substrate.

Hernaiz et al. [41] conducted a benchmark study of contact angles of graphene oxide, alumina and gold water-based nanofluids. They proposed a new correlation of the contact angle in dependency of droplet temperature $(t)$ and volume $\left(V_{d r}\right)$ based on the results obtained at different research institutes [41]:

$$
\theta_{f l}\left(t, V_{d r}\right)=a_{0}+a_{t} t+a_{V} V_{d r}^{1 / 3}
$$

where $a_{0}, a_{t}$, and $a_{V}$ are coefficients depending on the type of investigated fluid. 
Coefficients in equation (2) for water and graphene oxide nanofluid are presented in Table 3. Parameters are characterised by high standard errors, but this is the first available correlation that allows for the computation of the contact angle on a stainless steel substrate (the same that was used in this study) for given nanofluids based on a wide range of experimental results. Unfortunately, no coefficients are available for silica nanofluid.

Table 3. Parameters in correlation of the contact angle proposed by Hernaiz et al [41].

\begin{tabular}{|l|c|c|c|}
\hline Sample & $\mathrm{a}_{0}\left[{ }^{\circ}\right]$ & $\mathrm{a}_{\mathrm{t}}\left[{ }^{\circ} /{ }^{\circ} \mathrm{C}\right]$ & $\mathrm{a}_{\mathrm{v}}\left[{ }^{\circ} / \mathrm{dm}\right]$ \\
\hline Water & $103.28 \pm 13.25$ & $-0.83 \pm 0.58$ & $-480.52 \pm 228.34$ \\
GO nanofluid & $183.08 \pm 44.08$ & $-4.39 \pm 1.88$ & $-797.57 \pm 504.53$ \\
\hline
\end{tabular}

Table 4 presents a comparison between the contact angles obtained experimentally and estimated using the above-mentioned correlation (Eq. 2). The differences between measurements and calculations do not exceed $8 \%$ in case of water and both GO samples and are included in the standard errors of parameters described in [41].

Table 4. Comparison of the contact angle measured experimentally (CA exp) and estimated from the correlation [41] (CA corr), Diff is the percentage difference between both values.

\begin{tabular}{|l|c|c|c|}
\hline Sample & CA exp [ ${ }^{\circ}$ ] & CA corr $\left[{ }^{\circ}\right]$ & Diff [\%] \\
\hline Water & 72.05 & 77.71 & $7.9 \%$ \\
GO nanofluid & 73.24 & 72.66 & $0.8 \%$ \\
GO after boiling & 73.61 & 71.52 & $2.8 \%$ \\
\hline
\end{tabular}

Çobanoğlu et al. [42] analysed if available theoretical models describing contact angle of single-phase liquids are suitable for the estimation of nanofluids. They investigated four types of water-based nanofluids - gold $(\mathrm{Au})$, graphene oxide $(\mathrm{GO})$, aluminium (I) oxide $\left(\mathrm{Al}_{2} \mathrm{O}_{3}\right)$, and silicon dioxide $\left(\mathrm{SiO}_{2}\right)-$ synthesised in the same procedure as the sample analysed in this paper. Among tested nanofluids, silica nanofluid showed the highest differences between experimental and calculated values. This was a result of high concentration ( $2 \%$ vol.) and additional effects, such as disjoining pressure, convective flow inside the droplet, etc. Considered models require details of the droplets (e.g. droplet baseline radius, apex height and curvature) that are not known before conducting experiments, so this approach is not practical for engineering applications.

Chinnam et al. [61] experimentally investigated contact angles at the solid-fluid-air interface formed by water, propylene glycol, and mixture of water and propylene glycol in a mass ratio of 40 to $60 \%$ on the glass surface. Then, four types of nanoparticles $\left(\mathrm{Al}_{2} \mathrm{O}_{3}, \mathrm{ZnO}, \mathrm{TiO}_{2}\right.$, and $\left.\mathrm{SiO}_{2}\right)$ were dispersed in 60:40 PG/W base fluid with concentrations between 0 and $6 \%$ and average particle sizes ranged from 15 to $50 \mathrm{~nm}$. Based on the statistical analysis of the results, they proposed the following correlation as a function of temperature $(t)$, volumetric concentration $(\varnothing)$, and the size of nanoparticles $\left(d_{p}\right)$ [61]:

$$
\frac{\theta_{n f}}{\theta_{b f}}\left(t, d_{p}, \emptyset\right)=a_{1} \phi^{2}+a_{2} \phi+b_{1}\left(\frac{t}{t_{o}}\right)+c_{1}\left(\frac{d_{p}}{d_{b f}}\right)+D
$$

where $t_{o}$ is reference temperature $\left(26^{\circ} \mathrm{C}\right) ; a_{1}, a_{2}, b_{1}, c_{1}$, and $\mathrm{D}$ are coefficients described in Table 5; and $d_{b f}$ is fluid molecule parameter [61]:

$$
d_{b f}=0.1\left[\frac{6 M}{N_{A} \pi \rho_{b f 0}}\right]^{1 / 3}
$$


where $M$ is molecular weight, $N_{A}$ Avogadro number, $\rho_{b f 0}$ is density of the base fluid at $20^{\circ} \mathrm{C}$.

Table 5. Coefficients in eq. (3) for Chinnam [61] correlation on contact angle of PG/W-based nanofluids containing $\mathrm{Al}_{2} \mathrm{O}_{3}, \mathrm{ZnO}, \mathrm{TiO}_{2}$, and $\mathrm{SiO}_{2}$ nanoparticles on glass surface.

\begin{tabular}{|c|c|}
\hline Coefficient in eq. (2) [35] & Value \\
\hline$a_{1}$ & 10.5194 \\
$a_{2}$ & -4.17912 \\
$b_{1}$ & -0.00252388 \\
$c_{1}$ & -0.000674063 \\
$D$ & 0.989345 \\
\hline
\end{tabular}

The comparison of experimental results with the values calculated from correlation (eq. 3 ) is shown in Table 6 . The correlation overestimates the contact angle value by about $24 \%$, and should not be used for water-based nanofluid. Water-based silica nanofluid is characterised by better wettability than PG/W-based nanofluid, although pure 60:40 PG/W base fluid is characterised by a significantly lower contact angle than DI water [61]. This suggests that the influence of nanoparticles on a waterbased nanofluid is even stronger than for 60:40 PG/W-based nanofluid.

Table 6. Comparison of the contact angle measured experimentally (CA exp) and estimated from the correlation proposed by Chinnam et al [61] (CA corr).

\begin{tabular}{|l|c|c|c|}
\hline Sample & CA $\exp ^{{ }^{\circ}}{ }^{\text {] }}$ & CA corr $^{\left.{ }^{\circ}\right]}$ & Diff [\%] \\
\hline Silica nanofluid & 50.1 & 62.2 & $24.2 \%$ \\
Silica after boiling & 49.8 & 62.2 & $24.9 \%$ \\
\hline
\end{tabular}

Chinnam et al. [61] also presented a linear correlation for given nanofluids in dependence of temperature. For $\mathrm{SiO}_{2}$-based nanofluid, the correlations are as follows:

Table 7. Linear correlations for silica nanofluid based on concentration [61] and difference (Diff) between the contact angle measured experimentally (CA exp) and estimated from the correlation [35] (CA corr). Temperature used for these correlations should be in $\mathrm{K}$.

\begin{tabular}{|l|c|c|c|c|}
\hline Sample in [35] & Correlation & CA exp [ $\left.{ }^{\circ}\right]$ & CA corr [ ${ }^{\circ}$ ] & Diff [\%] \\
\hline $2 \% \mathrm{SiO}_{2}, 30 \mathrm{~nm}$ & $\theta_{n f}=-0.801 t+74.75$ & 50.1 & 57.8 & $15.2 \%$ \\
$6 \% \mathrm{SiO}_{2}, 20 \mathrm{~nm}$ & $\theta_{n f}=-0.5497 t+59.14$ & 50.1 & 47.5 & $5.2 \%$ \\
\hline
\end{tabular}

Changing PG/W to distilled water as a base fluid in $\mathrm{SiO}_{2}$ nanofluid acts as increasing concentration of nanoparticles. This is in opposition to the trends of contact angle results for the base fluid, and thus the contact angle of silica nanofluids should be investigated more thoroughly in the future. Due to the limited number of investigated temperatures in this study, there is no possibility to develop new, reliable correlations for silica nanofluid.

\section{- Copper substrate (tube)}

The next analysed surface was a smooth copper tube with roughness of about $0.6 \mu \mathrm{m}$. The possibility of tube curvature adjustment in the equipment software allowed the conduction of these experiments. Each measurement took 15 seconds and started after droplet deposited on the surface. An illustrative water droplet on a copper tube with adjusted curvature is presented in Fig 7. 


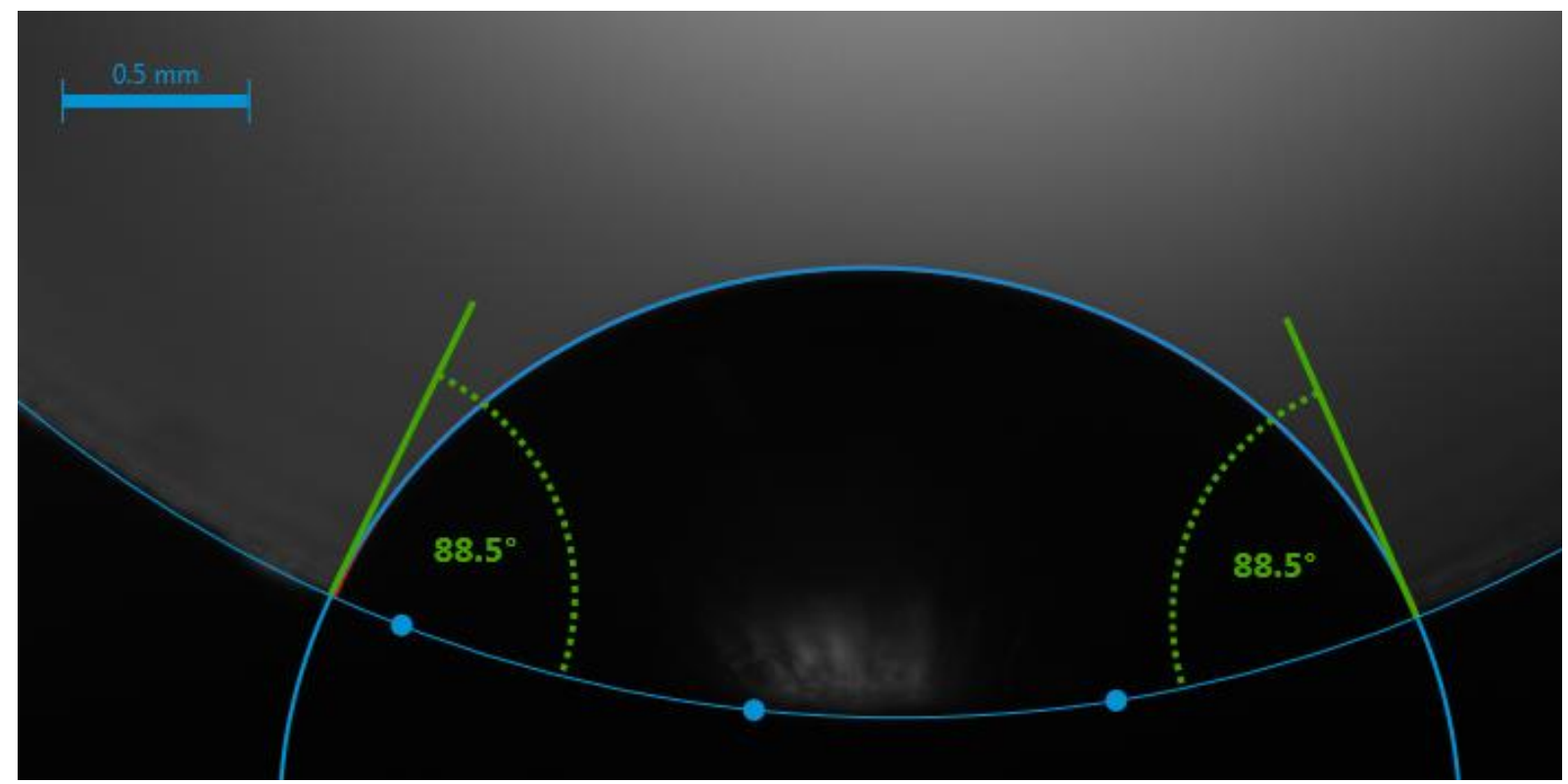

Fig. 7. Contact angle measurement of water droplet deposited on a copper tube with adjusted curvature.

Table 8 presents the averaged values of contact angles between the smooth copper tube and droplets of investigated fluids at the ambient temperature. Although the substrate material, curvature, and absolute values of contact angle differ (the values are higher for the copper substrate), the trends are similar to those on the stainless-steel substrate. The droplets of both silica samples displayed the lowest contact angle. Results obtained for the fresh silica nanofluid had the highest standard deviation due to the highest concentration of nanoparticles.

Table 8. Averaged contact angles between copper tube and droplets of investigated fluids at the ambient temperature. $C A$ - contact angle, $\sigma$-standard deviation, Vol-volume of the droplet during measurement, Temp - current ambient temperature.

\begin{tabular}{|l|ccc|}
\hline Sample & $\mathbf{C A} \pm \sigma\left[^{\circ}\right]$ & Vol $[\mu \mathrm{L}]$ & Temp $\left[{ }^{\circ} \mathbf{C}\right]$ \\
\hline Water & $90.7 \pm 4.66$ & 6.1 & 21.6 \\
Silica nanofluid & $79.6 \pm 6.16$ & 5.6 & 22.7 \\
Silica after boiling & $74.7 \pm 3.46$ & 5.0 & 22.5 \\
GO nanofluid & $94.8 \pm 4.42$ & 6.6 & 21.1 \\
GO after boiling & $89.0 \pm 2.63$ & 4.8 & 22.6 \\
\cline { 2 - 4 } & &
\end{tabular}

The standard deviation for measurements of water on a copper substrate is not the lowest, as it was the case for the stainless steel substrate. Most of the samples had similar standard deviations (in the range of $\left.3.46^{\circ}-4.66^{\circ}\right)$. This could be a result of an external error, for example higher possibility of deposition of the droplet on the side of the tube (presence of weak advancing/receding dynamic contact angles), or necessary adjustment for the tube curvature, which is more complicated than adjustment for the horizontal surface.

Similar to the stainless steel substrate, samples based on graphene oxide flakes formed droplets characterised by contact angles similar to that of water within an experimental uncertainty. In opposition to the horizontal steel surface, a decrease in contact angle for the after-use sample compared to the fresh nanofluid was noticed on the copper tube. Both graphene oxide samples were characterised by worse wettability on the copper tube than silica nanofluid samples. 


\section{Conclusions}

The paper investigates the effect of boiling on the surface tension and contact angle of two nanofluids: one containing the graphene oxide flakes and one with the silica spherical nanoparticles. The above-presented results complement earlier studies focused on boiling characteristics and heat transfer capacity of the thermosyphon $[7,14]$. Current paper is focused on the characterization of samples before and after a series of boiling experiments. Surface tension of before-use and after-use nanofluid was measured in the temperature range of $15-75^{\circ} \mathrm{C}$ and compared with the values for water. Additional measurements of graphene oxide nanofluids with and without addition of sodium dodecyl sulfate surfactant (SDS) were performed to distinguish the effect caused by graphene oxide flakes and surfactant itself. Contact angle measurements were conducted at the ambient temperature on two different surfaces: a stainless-steel substrate and a smooth copper tube. The results for stainless steel substrate were compared with existing correlations, but no similar study was found for a copper tube.

The conclusions are as follows:

- Silica nanofluid (2 vol.\%) was characterised by $4-9 \%$ lower surface tension than the base fluid (water) for a temperature range of $15-75^{\circ} \mathrm{C}$. In comparison with pure water, the contact angles of silica nanofluid were approx. $31 \%$ lower on the stainless-steel substrate and 12 $18 \%$ on the copper tube. Reduced surface tension of silica nanofluid had a significant impact on boiling behaviour in the thermosyphon. It affected boiling regimes and suppressed geysering [7].

- The graphene oxide nanofluid showed surface tension and contact angles similar to water due to the low concentration of graphene flakes $(0.1 \mathrm{~g} / \mathrm{L})$. The impact of graphene oxide nanofluid on the heat transfer capacity of the thermosyphon [14] was not related to its surface tension or wettability.

- Differences in analysed properties of all samples before and after boiling were negligible smaller than the measurement uncertainties. Silica nanofluid that was previously boiled in the thermosyphon had slightly higher averaged surface tension and smaller contact angles compared to the fresh nanofluid. This could be an effect of reduced concentration of particles in the sample after boiling due to deposition of nanoparticles on the inner wall of the thermosyphon. In the case of graphene oxide nanofluid, there were actually no trends of visible changes.

Further research is required to address the behaviour nanofluids in thermosyphons and the influence of boiling on their properties. Special focus should be put on a wide range of operating conditions, investigation how type and concentration of nanofluids affects the results, and how boiling time influences the change in nanofluid characteristics. Nanofluids are often studied under conditions rarely met in the real applications. It is especially true for low pressure devices that require further studies and development of proper measurement techniques.

\section{Acknowledgements}

This research was supported by EU COST Action CA15119: Overcoming Barriers to Nanofluids Market Uptake and STSM Grants Ref. COST-STSM- CA15119-45026, and CA15119-46347. A.K. acknowledges the grant no 2016/23/N/ST8/00252 from National Science Centre in Poland for the financial support related to the experimental research in the thermosyphon and samples of tested nanofluids. P.E. acknowledges the European Union through the European Regional Development Fund (ERDF), the 
Ministry of Higher Education and Research, the French region of Brittany and Rennes Métropole for the financial support related to the device used in this study for surface tension and contact angle measurements. GŻ acknowledges Michał Wanic (Rzeszow University of Technology) for technical assistance.

\section{References}

[1] D.A. Reay, P.A. Kew, Heat Pipes. Theory, Design and Applications, Fifth edit, ButterworthHeinemann, Oxford, 2006. https://doi.org/10.1017/СBO9781107415324.004.

[2] A. Faghri, Heat Pipes: Review, Opportunities and Challenges, Front. Heat Pipes. 5 (2014). https://doi.org/10.5098/fhp.5.1.

[3] N. Miljkovic, E.N. Wang, Modeling and optimization of hybrid solar thermoelectric systems with thermosyphons, Sol. Energy. 85 (2011) 2843-2855. https://doi.org/10.1016/j.solener.2011.08.021.

[4] G. Rice, Heat Pipes, THERMOPEDIA A-to-Z Guid. to Thermodyn. Heat Mass Transf. Fluids Eng. (2011). https://doi.org/10.1615/AtoZ.h.heat_pipes.

[5] M.H. Buschmann, R. Azizian, T. Kempe, J.E. Juliá, R. Martínez-Cuenca, B. Sundén, Z. Wu, A. Seppälä, T. Ala-Nissila, Correct interpretation of nanofluid convective heat transfer, Int. J. Therm. Sci. 129 (2018) 504-531. https://doi.org/10.1016/j.ijthermalsci.2017.11.003.

[6] ISO/TS 80004-2:2015 Nanotechnologies -- Vocabulary -- Part 2: Nano-objects, Int. Organ. Stand. (2015). https://www.iso.org/obp/ui/\#iso:std:iso:ts:80004:-2:ed-1:v1:en (accessed October 1, 2018).

[7] A. Kujawska, B. Zajaczkowski, L.M. Wilde, M.H. Buschmann, Geyser boiling in a thermosyphon with nanofluids and surfactant solution, Int. J. Therm. Sci. (2019) 195-216. https://doi.org/10.1016/j.ijthermalsci.2019.02.001.

[8] O. Mahian, L. Kolsi, M. Amani, P. Estellé, G. Ahmadi, C. Kleinstreuer, J.S. Marshall, M. Siavashi, R.A. Taylor, H. Niazmand, S. Wongwises, T. Hayat, A. Kolanjiyil, A. Kasaeian, I. Pop, Recent advances in modeling and simulation of nanofluid flows-Part I: Fundamentals and theory, Phys. Rep. 790 (2018) 1-48. https://doi.org/10.1016/j.physrep.2018.11.004.

[9] M.H. Buschmann, Nanofluids in thermosyphons and heat pipes: Overview of recent experiments and modelling approaches, Int. J. Therm. Sci. 72 (2014) 1-17. https://doi.org/10.1016/j.ijthermalsci.2013.04.024.

[10] A.A. Walunj, F.Z. Pathan, A.A. Shaikh, A.K. Hussein, Heat Transfer Enhancement in Heat Pipe Using Nanofluid - A Review, (2015) 65-70.

[11] N.K. Gupta, A.K. Tiwari, S.K. Ghosh, Heat transfer mechanisms in heat pipes using nanofluids A review, Exp. Therm. Fluid Sci. 90 (2018) 84-100. https://doi.org/10.1016/j.expthermflusci.2017.08.013.

[12] L.L. Vasiliev, L.P. Grakovich, M.I. Rabetskii, L.L. Vasiliev, Jr., Heat Transfer Enhancement in Heat Pipes and Thermosyphons Using Nanotechnologies (Nanofluids, Nanocoatings, and Nanocomposites) As an Hp Envelope, Heat Pipe Sci. Technol. An Int. J. 4 (2013) 251-275. https://doi.org/10.1615/HeatPipeScieTech.2014011995.

[13] L.M. Poplaski, S.P. Benn, A. Faghri, Thermal performance of heat pipes using nanofluids, Int. J. Heat Mass Transf. 107 (2017) 358-371. https://doi.org/10.1016/j.ijheatmasstransfer.2016.10.111. 
[14] A. Wlazlak, B. Zajaczkowski, M. Woluntarski, M.H. Buschmann, Influence of graphene oxide nanofluids and surfactant on thermal behaviour of the thermosyphon, J. Therm. Anal.

Calorim. 136 (2019) 843-855. https://doi.org/10.1007/s10973-018-7632-x.

[15] A. Kujawska, R. Mulka, M.H. Buschmann, Z. Krolicki, B. Zajaczkowski, Impact of Silica Nanofluid Deposition on Thermosyphon Performance, Heat Transf. Eng. 0 (2020) 1-18. https://doi.org/10.1080/01457632.2020.1818413.

[16] M. Azizi, M. Hosseini, S. Zafarnak, M. Shanbedi, A. Amiri, Experimental analysis of thermal performance in a two-phase closed thermosiphon using graphene/water nanofluid, Ind. Eng. Chem. Res. (2013) 10015-10021. https://doi.org/10.1021/ie401543n.

[17] T. Parametthanuwat, S. Rittidech, A. Pattiya, A correlation to predict heat-transfer rates of a two-phase closed thermosyphon (TPCT) using silver nanofluid at normal operating conditions, Int. J. Heat Mass Transf. 53 (2010) 4960-4965.

https://doi.org/10.1016/j.ijheatmasstransfer.2010.05.046.

[18] M.M. Sarafraz, F. Hormozi, Experimental study on the thermal performance and efficiency of a copper made thermosyphon heat pipe charged with alumina-glycol based nanofluids, Powder Technol. 266 (2014) 378-387. https://doi.org/10.1016/j.powtec.2014.06.053.

[19] G. Huminic, A. Huminic, Heat transfer characteristics of a two-phase closed thermosyphons using nanofluids, Exp. Therm. Fluid Sci. 35 (2011) 550-557. https://doi.org/10.1016/j.expthermflusci.2010.12.009.

[20] T. Grab, U. Gross, U. Franzke, M.H. Buschmann, Operation performance of thermosyphons employing titania and gold nanofluids, Int. J. Therm. Sci. 86 (2014) 352-364. https://doi.org/10.1016/j.jithermalsci.2014.06.019.

[21] Z.H. Liu, X.F. Yang, G.S. Wang, G.L. Guo, Influence of carbon nanotube suspension on the thermal performance of a miniature thermosyphon, Int. J. Heat Mass Transf. 53 (2010) 19141920. https://doi.org/10.1016/j.ijheatmasstransfer.2009.12.065.

[22] X.F. Yang, Z.H. Liu, Application of Functionalized Nanofluid in Thermosyphon., Nanoscale Res. Lett. 6 (2011) 494. https://doi.org/10.1186/1556-276X-6-494.

[23] E. Forrest, E. Williamson, J. Buongiorno, L.W. Hu, M. Rubner, R. Cohen, Augmentation of nucleate boiling heat transfer and critical heat flux using nanoparticle thin-film coatings, Int. J. Heat Mass Transf. 53 (2010) 58-67.

https://doi.org/10.1016/j.ijheatmasstransfer.2009.10.008.

[24] X. Li, S.C. Pok Cheung, J. Tu, Nucleate boiling of dilute nanofluids - Mechanism exploring and modeling, Int. J. Therm. Sci. 84 (2014) 323-334.

https://doi.org/10.1016/j.ijthermalsci.2014.05.021.

[25] G. Moreno, J.R. Jeffers, S. Narumanchi, Effects of Pressure and a Microporous Coating on HFC$245 f a$ Pool Boiling Heat Transfer, J. Heat Transfer. 136 (2014) 101502. https://doi.org/10.1115/1.4027966.

[26] S. Vafaei, T. Borca-Tasciuc, Role of nanoparticles on nanofluid boiling phenomenon: Nanoparticle deposition, Chem. Eng. Res. Des. 92 (2014) 842-856. https://doi.org/10.1016/j.cherd.2013.08.007.

[27] L.L. Manetti, M.T. Stephen, P.A. Beck, E.M. Cardoso, Evaluation of the heat transfer enhancement during pool boiling using low concentrations of Al2O3-water based nanofluid, Exp. Therm. Fluid Sci. 87 (2017) 191-200.

https://doi.org/10.1016/j.expthermflusci.2017.04.018. 
[28] D.E. Kim, D.I. Yu, D.W. Jerng, M.H. Kim, H.S. Ahn, Review of boiling heat transfer enhancement on micro/nanostructured surfaces, Exp. Therm. Fluid Sci. 66 (2015) 173-196. https://doi.org/10.1016/j.expthermflusci.2015.03.023.

[29] G. Harish, V. Emlin, V. Sajith, Effect of surface particle interactions during pool boiling of nanofluids, Int. J. Therm. Sci. 50 (2011) 2318-2327. https://doi.org/10.1016/j.ijthermalsci.2011.06.019.

[30] P. Estellé, D. Cabaleiro, G. Żyła, L. Lugo, S.M.S. Murshed, Current trends in surface tension and wetting behavior of nanofluids, Renew. Sustain. Energy Rev. 94 (2018) 931-944. https://doi.org/10.1016/J.RSER.2018.07.006.

[31] J.D. Berry, M.J. Neeson, R.R. Dagastine, D.Y.C. Chan, R.F. Tabor, Measurement of surface and interfacial tension using pendant drop tensiometry, J. Colloid Interface Sci. 454 (2015) 226237. https://doi.org/10.1016/j.jcis.2015.05.012.

[32] J. Drelich, C. Fang, C.L. White, Measurement of interfacial tension in Fluid-Fluid Systems, Encycl. Surf. Colloid Sci. (2002) 3152-3166.

[33] M.H.U. Bhuiyan, R. Saidur, M.A. Amalina, R.M. Mostafizur, A.K.M.S. Islam, Effect of nanoparticles concentration and their sizes on surface tension of nanofluids, Procedia Eng. 105 (2015) 431-437. https://doi.org/10.1016/j.proeng.2015.05.030.

[34] M.H.U. Bhuiyan, R. Saidur, R.M. Mostafizur, I.M. Mahbubul, M.A. Amalina, Experimental investigation on surface tension of metal oxide-water nanofluids, Int. Commun. Heat Mass Transf. 65 (2015) 82-88. https://doi.org/10.1016/j.icheatmasstransfer.2015.01.002.

[35] J. Chinnam, D.K. Das, R.S. Vajjha, J.R. Satti, Measurements of the surface tension of nanofluids and development of a new correlation, Int. J. Therm. Sci. 98 (2015) 68-80. https://doi.org/10.1016/j.ijthermalsci.2015.07.008.

[36] G. Lu, Y.Y. Duan, X.D. Wang, Surface tension, viscosity, and rheology of water-based nanofluids: a microscopic interpretation on the molecular level, J. Nanoparticle Res. 16 (2014). https://doi.org/10.1007/s11051-014-2564-2.

[37] N. Ahammed, L.G. Asirvatham, S. Wongwises, Effect of volume concentration and temperature on viscosity and surface tension of graphene-water nanofluid for heat transfer applications, J. Therm. Anal. Calorim. 123 (2016) 1399-1409. https://doi.org/10.1007/s10973015-5034-x.

[38] Z.Z. Zheng, Experimental Investigation on Surface Tension of Water-Based Graphene Oxide Nanofluids, Adv. Mater. Res. 1082 (2014) 297-301. https://doi.org/10.4028/www.scientific.net/AMR.1082.297.

[39] D. Cabaleiro, H. Navas, A. Desforges, Dynamic Viscosity and Surface Tension of Stable Graphene Oxide and Reduced Graphene Oxide Aqueous Nanofluid, J. Nanofluids. 7 (2018) 18. https://doi.org/10.1166/jon.2018.1539.

[40] R. Kamatchi, S. Venkatachalapathy, B. Abhinaya Srinivas, Synthesis, stability, transport properties, and surface wettability of reduced graphene oxide/water nanofluids, Int. J. Therm. Sci. 97 (2015) 17-25. https://doi.org/10.1016/j.ijthermalsci.2015.06.011.

[41] M. Hernaiz, V. Alonso, P. Estellé, Z. Wu, B. Sundén, L. Doretti, S. Mancin, N. Çobanoğlu, Z.H. Karadeniz, N. Garmendia, M. Lasheras-Zubiate, L. Hernández López, R. Mondragón, R. Martínez-Cuenca, S. Barison, A. Kujawska, A. Turgut, A. Amigo, G. Huminic, A. Huminic, M.-R. Kalus, K.-G. Schroth, M.H. Buschmann, The contact angle of nanofluids as thermophysical property, J. Colloid Interface Sci. 547 (2019) 393-406. 
https://doi.org/10.1016/j.jcis.2019.04.007.

[42] N. Çobanoğlu, Z.H. Karadeniz, P. Estellé, R. Martínez-Cuenca, M.H. Buschmann, Prediction of Contact Angle of Nanofluids by Single-Phase Approaches, Energies. 12 (2019) 4558. https://doi.org/10.3390/en12234558.

[43] S. Vafaei, M.Z. Podowski, Analysis of the relationship between liquid droplet size and contact angle, Adv. Colloid Interface Sci. 113 (2005) 133-146.

https://doi.org/10.1016/j.cis.2005.03.001.

[44] J.T. Cieśliński, K.A. Krygier, Sessile droplet contact angle of water-Al2O3, water-TiO2and water-Cu nanofluids, Exp. Therm. Fluid Sci. 59 (2014) 258-263. https://doi.org/10.1016/j.expthermflusci.2014.06.004.

[45] S. Vafaei, T. Borca-Tasciuc, M.Z. Podowski, A. Purkayastha, G. Ramanath, P.M. Ajayan, Effect of nanoparticles on sessile droplet contact angle, Nanotechnology. 17 (2006) 2523-2527. https://doi.org/10.1088/0957-4484/17/10/014.

[46] A. Gimeno-Furio, N. Navarrete, R. Mondragon, L. Hernandez, R. Martinez-Cuenca, L. Cabedo, J.E. Julia, Stabilization and characterization of a nanofluid based on a eutectic mixture of diphenyl and diphenyl oxide and carbon nanoparticles under high temperature conditions, Int. J. Heat Mass Transf. (2017). https://doi.org/10.1016/j.ijheatmasstransfer.2017.05.097.

[47] J.S. Coursey, J. Kim, Nanofluid boiling: The effect of surface wettability, Int. J. Heat Fluid Flow. 29 (2008) 1577-1585. https://doi.org/10.1016/j.ijheatfluidflow.2008.07.004.

[48] A. Jaikumar, A. Gupta, S.G. Kandlikar, C.Y. Yang, C.Y. Su, Scale effects of graphene and graphene oxide coatings on pool boiling enhancement mechanisms, Int. J. Heat Mass Transf. 109 (2017) 357-366. https://doi.org/10.1016/j.ijheatmasstransfer.2017.01.110.

[49] B.J. Zhang, J. Park, K.J. Kim, Augmented boiling heat transfer on the wetting-modified three dimensionally-interconnected alumina nano porous surfaces in aqueous polymeric surfactants, Int. J. Heat Mass Transf. 63 (2013) 224-232.

https://doi.org/10.1016/j.ijheatmasstransfer.2013.03.064.

[50] S.J. Kim, I.C. Bang, J. Buongiorno, L.W. Hu, Effects of nanoparticle deposition on surface wettability influencing boiling heat transfer in nanofluids, Appl. Phys. Lett. 89 (2006). https://doi.org/10.1063/1.2360892.

[51] S.J. Kim, C. Bang, J. Buongiorno, L.W. Hu, Study of pool boiling and critical heat flux enhancement in nanofluids, Bull. Polish Acad. Sci. 55 (2007) 211-216. https://doi.org/10.1115/IMECE2007-41697.

[52] M.M. Sarafraz, F. Hormozi, M. Silakhori, S.M. Peyghambarzadeh, On the fouling formation of functionalized and non-functionalized carbon nanotube nano-fluids under pool boiling condition, Appl. Therm. Eng. 95 (2016) 433-444. https://doi.org/10.1016/j.applthermaleng.2015.11.071.

[53] Q.T. Pham, T.I. Kim, S.S. Lee, S.H. Chang, Enhancement of critical heat flux using nano-fluids for Invessel Retention-External Vessel Cooling, Appl. Therm. Eng. 35 (2012) 157-165. https://doi.org/10.1016/j.applthermaleng.2011.10.017.

[54] B. Truong, L. wen Hu, J. Buongiorno, T. McKrell, Modification of sandblasted plate heaters using nanofluids to enhance pool boiling critical heat flux, Int. J. Heat Mass Transf. 53 (2010) 85-94. https://doi.org/10.1016/j.jjheatmasstransfer.2009.10.002.

[55] A. Gimeno-Furio, L. Hernandez, S. Barison, F. Agresti, G. Bottaro, D. Cabaleiro, L. Doretti, S. 
Mancin, Effects of Carbon Nanohorn Based Nanofluids Pool Boiling on Optical Properties and Wettability of Different Metal Surfaces, Heat Transf. Eng. (2020).

https://doi.org/10.1080/01457632.2020.1818407.

[56] A. Ehle, S. Feja, M.H. Buschmann, Temperature Dependency of Ceramic Nanofluids Shows Classical Behavior, J. Thermophys. Heat Transf. 25 (2011) 378-385.

https://doi.org/10.2514/1.T3634.

[57] M. Wanic, D. Cabaleiro, S. Hamze, J. Fal, P. Estellé, G. Żyła, Surface tension of ethylene glycolbased nanofluids containing various types of nitrides: An experimental study, J. Therm. Anal. Calorim. 139 (2020) 799-806. https://doi.org/10.1007/s10973-019-08512-1.

[58] D. Cabaleiro, S. Hamze, J. Fal, M.A. Marcos, P. Estellé, G. Żyła, Thermal and Physical Characterization of PEG Phase Change Materials Enhanced by Carbon-Based Nanoparticles, Nanomaterials. 10 (2020) 1168. https://doi.org/10.3390/nano10061168.

[59] R. Gómez-Villarejo, T. Aguilar, S. Hamze, P. Estellé, J. Navas, Experimental analysis of waterbased nanofluids using boron nitride nanotubes with improved thermal properties, J. Mol. Liq. 277 (2019) 93-103. https://doi.org/10.1016/j.molliq.2018.12.093.

[60] I.H. Bell, J. Wronski, S. Quoilin, V. Lemort, Pure and Pseudo-pure Fluid Thermophysical Property Evaluation and the Open-Source Thermophysical Property Library CoolProp., Ind. Eng. Chem. Res. 53 (2014) 2498-2508. https://doi.org/10.1021/ie4033999.

[61] J. Chinnam, D. Das, R. Vajjha, J. Satti, Measurements of the contact angle of nanofluids and development of a new correlation, Int. Commun. Heat Mass Transf. 62 (2015) 1-12. https://doi.org/10.1016/j.icheatmasstransfer.2014.12.009. 